\title{
Anterior cingulate hyperactivations during negative emotion processing among men with schizophrenia and a history of violent behavior
}

This article was published in the following Dove Press journal:

Neuropsychiatric Disease and Treatment

I5 June 2016

Number of times this article has been viewed

\author{
Andràs Tikàsz ${ }^{1,2}$ \\ Stéphane Potvin ${ }^{1,2}$ \\ Ovidiu Lungu ${ }^{2-4}$ \\ Christian C Joyal ${ }^{5,6}$ \\ Sheilagh Hodgins ${ }^{2,5}$ \\ Adrianna Mendrek ${ }^{1,7}$ \\ Alexandre Dumais ${ }^{1,2,5}$ \\ 'Centre de recherche de l'Institut \\ Universitaire en Santé Mentale de \\ Montréal, ${ }^{2}$ Department of Psychiatry, \\ University of Montreal, ${ }^{3}$ Centre de \\ recherche de I'Institut Universitaire \\ de Gériatrie de Montréal, ${ }^{4}$ Centre for \\ Research in Aging, Donald Berman \\ Maimonides Geriatric Centre, \\ ${ }^{5}$ Institut Philippe-Pinel de Montréal, \\ ${ }^{6}$ Department of Psychology, Université \\ du Québec à Trois-Rivières, Trois- \\ Rivières, 'Department of Psychology, \\ Bishop's University, Sherbrooke, QC, \\ Canada
}

Correspondence: Alexandre Dumais Institut Philippe-Pinel de Montréal, 10905 Henri-Bourassa Est, Montréal, QC HIC IHI, Canada

$\mathrm{Tel}+|5| 4648846 \mid$

Email alexandre.dumais@umontreal.ca
Background: Evidence suggests a 2.1-4.6 times increase in the risk of violent behavior in schizophrenia compared to the general population. Current theories propose that the processing of negative emotions is defective in violent individuals and that dysfunctions within the neural circuits involved in emotion processing are implicated in violence. Although schizophrenia patients show enhanced sensitivity to negative stimuli, there are only few functional neuroimaging studies that have examined emotion processing among men with schizophrenia and a history of violence.

Objective: The present study aimed to identify the brain regions with greater neurofunctional alterations, as detected by functional magnetic resonance imaging during an emotion processing task, of men with schizophrenia who had engaged in violent behavior compared with those who had not.

Methods: Sixty men were studied; 20 with schizophrenia and a history of violence, 19 with schizophrenia and no violence, and 21 healthy men were scanned while viewing positive, negative, and neutral images.

Results: Negative images elicited hyperactivations in the anterior cingulate cortex (ACC), left and right lingual gyrus, and the left precentral gyrus in violent men with schizophrenia, compared to nonviolent men with schizophrenia and healthy men. Neutral images elicited hyperactivations in the right and left middle occipital gyrus, left lingual gyrus, and the left fusiform gyrus in violent men with schizophrenia, compared to the other two groups.

Discussion: Violent men with schizophrenia displayed specific increases in ACC in response to negative images. Given the role of the ACC in information integration, these results indicate a specific dysfunction in the processing of negative emotions that may trigger violent behavior in men with schizophrenia.

Keywords: schizophrenia, violence, negative emotions, salience, anterior cingulate cortex, fMRI

\section{Introduction}

According to the World Health Organization, ${ }^{1}$ over 21 million people worldwide suffer from schizophrenia. Of particular concern is the evidence showing an increased risk of aggressive and violent behavior (severe assaults, attempted murder, homicide) among people with schizophrenia compared to the general population. ${ }^{2-6}$ Although most people with schizophrenia are not violent, ${ }^{7,8}$ individuals suffering from schizophrenia were found to be 2.1-4.6 times more likely to commit a violent crime or engage in violent behavior than the general population, even when taking into account socioeconomic status (SES), comorbid substance use, and personality disorders. ${ }^{2,9,10}$ In addition to 
promoting stigmatization and victimization of all persons with mental health problems, ${ }^{11}$ violent behavior by persons with schizophrenia has important consequences for the health and criminal justice systems, as shown by increasing numbers of forensic hospitals, longer periods in hospital, ${ }^{12,13}$ and increased rates of incarceration, ${ }^{14}$ all of which increase costs. Given that these consequences added to the suffering of the victims, their families, and the perpetrators, it is imperative to identify the neural mechanisms underlying violence in schizophrenia. A better understanding of these mechanisms would allow the development of effective interventions to prevent violent behavior.

Current theories propose that the processing of negative emotions (fear, anger) is defective in violent individuals. ${ }^{15,16}$ In fact, emotional instability was observed in adult offenders, ${ }^{17,18}$ as well as maladaptive coping with negative affect ${ }^{15}$ and oversensitivity to negative stimuli ${ }^{19}$ has been reported in aggressive men. Moreover, the processing of negative emotions, especially anger, was shown to be a factor in precipitating violent behavior and aggression. ${ }^{20,21}$ As the processing of negative emotions is important in violence, some postulates about the neural underpinnings of violent behavior have been founded in the literature of emotion processing. Considering that negative emotions are processed by a system involving the orbitofrontal cortex, amygdala, and anterior cingulate cortex (ACC), it has been proposed that dysfunctions within this system might be implicated in violence and aggression. ${ }^{22}$ Neuroimaging studies of violent individuals have generally supported this assumption. ${ }^{23}$ Given the association between negative affect (anger) and violent behavior in psychotic disorders, ${ }^{21}$ similar abnormalities in the amygdala-orbitofrontal system might be expected in violent men with schizophrenia $(\mathrm{SCZ}+\mathrm{V})$ as in violent men who do not have psychosis. ${ }^{24,25}$ However, such neural mechanisms have been investigated to a considerably lesser extent among SCZ+V men.

More neuroimaging studies have investigated structural than functional neural markers of violent behavior among people with schizophrenia. Among $\mathrm{SCZ}+\mathrm{V}$, studies have reported reduced brain volumes in the hippocampus, ${ }^{26-28}$ parahippocampus, ${ }^{28}$ amygdala, ${ }^{29} \mathrm{ACC},{ }^{30}$ orbitofrontal cortex,${ }^{27}$ cerebellum and supramarginal gyrus, ${ }^{31}$ and increased gray matter volumes in the putamen. ${ }^{26}$ Men with schizophrenia and a history of conduct disorder prior to age 15 have been shown to display increased gray matter volumes in the hypothalamus, right precuneus, and right inferior parietal cortex. ${ }^{32}$ Moreover, men with schizophrenia and high levels of aggressive behavior displayed larger orbitofrontal cortex ${ }^{33}$ and caudate volumes. ${ }^{34}$ To some extent, these structural gray matter alterations occur primarily in the frontal cortex and limbic system where emotion processing dysfunctions have been detected among SCZ $+\mathrm{V} \cdot{ }^{24,35,36}$ However, the currently available results are not consistent.

There are few functional neuroimaging studies that have examined emotion processing among $\mathrm{SCZ}+\mathrm{V}$. Relative to men with SCZ with low psychopathic traits, SCZ patients characterized by high levels of psychopathic traits showed blunted amygdala responses to fearful faces. ${ }^{37}$ Relative to nonpsychotic individuals diagnosed with antisocial personality disorder, $\mathrm{SCZ}+\mathrm{V}$ displayed greater activity in the thalamus and the caudate nucleus in response to threat stimuli. ${ }^{16}$ Finally, Hoptman et $\mathrm{al}^{38}$ reported reduced functional connectivity at resting state between the amygdala and prefrontal regions in $\mathrm{SCZ}+\mathrm{V}$. Overall, these results tentatively suggest that abnormalities in the amygdalaorbitofrontal system might be expected among $\mathrm{SCZ}+\mathrm{V}$ as in violent men without psychosis. ${ }^{24}$ However, these studies are limited by small sample sizes and/or lack of adequate comparison groups, as well as omission of positive emotions from the investigated affects. Even though most theories regarding emotion processing in violence concern negative affect, ${ }^{22}$ examining the processing of positive stimuli could be informative as studies have found reward-processing to be impaired in schizophrenia ${ }^{39}$ and violent individuals to be especially sensitive to immediate reward. ${ }^{40}$ Of further interest, Cohen and Minor ${ }^{41}$ have noted that schizophrenia is associated with an aversion to neutral stimuli. Functional magnetic resonance imaging (fMRI) findings show that persons with schizophrenia assign abnormal salience to neutral material. ${ }^{42-44}$ Therefore, it is also important to explore the neural response to neutral stimuli when examining emotional processing in $\mathrm{SCZ}+\mathrm{V}$.

Overall, knowledge of emotion processing in $\mathrm{SCZ}+\mathrm{V}$ is scarce and inconclusive. Using adequate control groups, we sought to identify brain regions with neurofunctional alterations among $\mathrm{SCZ}+\mathrm{V}$ compared to men with schizophrenia who have no history of violence (SCZ-V) and healthy controls, during an fMRI emotion processing task. Responses to negative, positive, and neutral emotions were assessed.

\section{Methods}

\section{Participants}

Thirty-nine male outpatients with schizophrenia or schizoaffective disorder (DSM-IV criteria; age 18-55 years) were recruited from forensic and general psychiatric hospitals. They were divided into two groups: 20 SCZ+V and 19SCZ-V. In accordance 
with the MacArthur study, serious violence was defined as a history of armed aggression resulting in injuries or death. ${ }^{45}$ Antecedents of serious violence were assessed based on clinical interview (Structured Clinical Interview for DSM-IV), ${ }^{46}$ self-reports (MacArthur Community Violence Instrument), ${ }^{45}$ and clinical files. All patients were stabilized on antipsychotic medication that had not changed within the last 2 months. Antipsychotic dosage was calculated using chlorpromazine equivalents. ${ }^{47}$ Symptom severity was evaluated with the Positive and Negative Syndrome Scale, ${ }^{48}$ which yield five subscores (ie, positive, negative, disorganization/cognitive, excitation, depression) according to Lindenmayer et al's ${ }^{49}$ five-factor model of schizophrenia. Urine drug screenings were administered.

The control group included 21 men with no history of violent behavior. Controls were screened with the nonpatient edition of the Structured Clinical Interview for DSM-IV. ${ }^{46}$

All participants were free of concomitant neurological disorders and substance use disorders (lifetime, for controls; in the last 12 months, for SCZ+V and SCZ-V). No participant had an IQ lower than 70 or MRI contraindications. Parental SES was assessed according to the National Occupational Classification. ${ }^{50}$ Finally, as in prior studies on violence, ${ }^{51}$ we calculated the number of DSM-IV diagnostic criteria for antisocial personality disorder ${ }^{46}$ that were met by each participant. The score ranged from no criterion to seven criteria.

\section{Ethical approval}

The patients were recruited by clinical staff that they knew. After having the study explained to them, all participants signed a consent form agreeing to interviews, an MRI, and the patients consented to giving access to their medical and criminal files. The study was approved by the local ethics committees from the Regroupement de Neuroimagerie du Québec, the Centre de recherche de l'Institut Universitaire en Santé Mentale de Montréal, and the Institut Philippe-Pinel de Montréal.

\section{Experimental procedure and task}

During fMRI, participants viewed blocks of emotionally positive, negative, and neutral pictures from the International Affective Picture System (IAPS). ${ }^{52}$ These pictures were matched for content (people, animals, landscapes), visual complexity and color, and grouped based on valence and arousal intensity (using the IAPS normative data), resulting in five experimental conditions: high arousal/positive, high arousal/negative, low arousal/positive, low arousal/negative, and neutral. Each condition was presented in separate blocks lasting 48.5 seconds, interceded by 16 -second rest periods. To ensure that participants attended to the images, they were asked to press a button whenever they saw a person in the picture. Each block contained ten images of one specific experimental condition, and each block type (high arousal/ positive, high arousal/negative, low arousal/positive, low arousal/negative) was repeated two times (except the neutral block, which was repeated four times). Each picture appeared for 3,000 ms followed by a blank screen with a fixation point for an average of 1.75 seconds (average interstimulus interval 4.75 seconds). The order of presentation of blocks was pseudorandomized. At the end of the fMRI session, participants were asked to rate the photographs in each block, on a scale ranging from 0 (absence of any emotional reaction) to 8 (strongest emotion ever felt in one's lifetime).

\section{Neuroimaging acquisition parameters}

Whole-brain fMRI was performed using an echoplanar imaging sequence measuring blood oxygenation leveldependent (BOLD) signal $(\mathrm{TR}=3,000 \mathrm{~ms}$; $\mathrm{TE}=30 \mathrm{~ms}$; $\mathrm{FA}=90^{\circ}$; matrix $=64 \times 64$; voxel size $=3.5 \mathrm{~mm}^{3} ; 41$ slices $)$. The functional slices were oriented in transverse plane and were angled to be parallel to the AC-PC line. An inline retrospective motion correction algorithm was employed while the echoplanar images were acquired. Individual high-resolution coplanar anatomical images were also acquired during the same scanning session (three-dimensional, spoiled gradient echo sequence; $\mathrm{TR}=19 \mathrm{~ms} ; \mathrm{TE}=4.92 \mathrm{~ms} ; \mathrm{FA}=25^{\circ}$; matrix size $=256 \times 256$; voxel size $=1 \mathrm{~mm}^{3} ; 176$ slices .

\section{Analysis of $\mathrm{fMRI}$ data}

fMRI data was analyzed with Brain Voyager QX software (Brain Innovation, Maastricht, the Netherlands). Functional images were slice-time-corrected, corrected for motion artifacts ( $\leq 2 \mathrm{~mm}$; all fMRI images were usable), highpass-filtered (two cycles per time course), coregistered to the corresponding anatomical image, spatially normalized to the Talairach space, ${ }^{53}$ and spatially smoothed with a 3D isotropic Gaussian kernel (8 mm FWHM).

We used a standard peak detection approach and a general linear model to identify the cerebral changes associated with emotion processing. Five predictors of interest, corresponding to the experimental conditions/blocks, were convolved with the hemodynamic response function estimated using the double- $\gamma$ model, ${ }^{54}$ and a first-order autoregression model was used to account for serial correlations. Initially, a first-level analysis was performed to investigate individual brain activation maps associated with the primary contrasts of interest 
([High Negative + Low Negative] $>$ Neutral; orthogonal) ([High Positive + Low Positive] $>$ Neutral; orthogonal). The (Neutral $>$ Rest) contrast was also examined. A second-level random-effects model was then computed to investigate the pattern of activations during emotion processing comparing the three groups. ${ }^{55}$ Between-group differences in clinical variables were considered as covariates in fMRI group comparisons.

The statistical threshold for significance was determined by Monte Carlo simulation. ${ }^{56}$ Assuming a voxel-level threshold of $P<0.001$ (10,000 simulations), a cluster size of $343 \mathrm{~mm}^{3}$ was required to correct for multiple comparisons at $P<0.05$. When relevant, we identified common activations between contrasts by performing spatial conjunction analyses, using the "Volume of Interest" option of Brain Voyager. For each cluster found to significantly differ between groups in the spatial conjunction analyses, the individual changes in BOLD signal (eg, $\beta$-values) were extracted and used to visually display results and to perform correlation analyses between regional BOLD responses and clinical variables (eg, emotional ratings, antisocial traits) within subgroups.

\section{Statistical analysis of the clinical data}

For continuous data, between-group differences were examined using analyses of variances. Pair-wise comparisons were performed using Tukey's HSD tests. For dichotomic data, $\chi^{2}$ tests were used. For pair-wise comparisons, Bonferroni correction was applied.

\section{Results}

\section{Characteristics of the participants}

Table 1 presents comparisons of the three groups of participants. No differences were detected in age, handedness, and ratings of positive and negative images (all $P$-values $>0.05$ ). $\mathrm{SCZ}+\mathrm{V}$ had lower parental SES than controls $(P=0.013)$. SCZ participants, with and without violent behavior, did not differ as to primary diagnoses (schizophrenia vs schizoaffective disorder), age of onset, illness duration, negative symptoms, chlorpromazine equivalents, and the proportion of SCZ patients treated with clozapine (all $P>0.05$ ). However, $\mathrm{SCZ}+\mathrm{V}$ presented fewer positive and disorganized symptoms than SCZ-V $(P<0.010$ and $P=0.010$, respectively). Finally, SCZ $+\mathrm{V}$ assigned more emotional significance to neutral images than controls, but this result did not achieve significance $(P=0.07)$, and there was no significant difference between schizophrenia subgroups $(P>0.05)$.

\section{Groups comparisons of neural activity during presentation of negative pictures}

As presented in Table 2, for the Negative minus Neutral contrast, relative to $\mathrm{SCZ}-\mathrm{V}, \mathrm{SCZ}+\mathrm{V}$ showed increased activations in the lingual gyrus, the right middle frontal gyrus, the right inferior frontal gyrus, the bilateral globus pallidus, the

Table I Characteristics of participants

\begin{tabular}{|c|c|c|c|c|}
\hline & $S C Z+V(n=20)$ & $\operatorname{SCZ}-V(n=19)$ & Healthy controls $(n=2 I)$ & Significance \\
\hline Age in years, mean (SE) & $30.0(1.6)$ & $31.4(1.7)$ & $30.9(1.7)$ & $F=0.2 ; P=0.842$ \\
\hline Parental SES (SE) & $3.4(0.3)$ & $2.9(0.1)$ & $2.4(0.2)$ & $F=4.4 ; P=0.017^{*}$ \\
\hline Handedness, \% right & 90.0 & 78.9 & 85.7 & $\chi^{2}=4.0 ; P=0.400$ \\
\hline Diagnoses & $6 \mathrm{SA}$ & $3 \mathrm{SA}$ & - & $\chi^{2}=I . I ; P=0.292$ \\
\hline Age of onset in years (SE) & $21.0(1.1)$ & $20.8(0.8)$ & - & $F=0.01 ; P=0.909$ \\
\hline Duration of illness (SE) & $9.5(4.8)$ & $10.6(7.5)$ & - & $F=0.3 ; P=0.609$ \\
\hline \multicolumn{5}{|l|}{ PANSS } \\
\hline Positive (SE) & $9.1(2.4)$ & I2.I (0.8) & - & $F=9.6 ; P=0.010$ \\
\hline Negative (SE) & $12.9(5.5)$ & I5.5 (I.3) & - & $F=2.0 ; P=0.166$ \\
\hline Disorganization (SE) & $6.8(1.9)$ & $8.5(0.4)$ & - & $F=7.4 ; P=0.010$ \\
\hline Excitation (SE) & $8.3(3.0)$ & $7.5(0.6)$ & - & $F=0.6 ; P=0.433$ \\
\hline Depression (SE) & $6.5(2.3)$ & 7.I (0.4) & - & $F=0.7 ; P=0.416$ \\
\hline \multicolumn{5}{|l|}{ Ratings } \\
\hline Positive images (SE) & $4.6(0.3)$ & $4.8(0.3)$ & $4.4(0.3)$ & $F=0.3 ; P=0.784$ \\
\hline Negative images (SE) & $5.3(0.4)$ & $5.3(0.3)$ & $5.1(0.3)$ & $F=0.5 ; P=0.603$ \\
\hline Neutral images (SE) & $2.4(0.4)$ & $2.1(0.5)$ & $1.2(0.3)$ & $F=2.8 ; P=0.072 *$ \\
\hline Chlorpromazine equivalents in mg (SE) & $846.9(170.7)$ & $654.4(74.7)$ & - & $F=I .1 ; P=0.309$ \\
\hline Clozapine (n) & 6 & 9 & - & $\chi^{2}=1.2 ; P=0.265$ \\
\hline
\end{tabular}

Note: Significant results are shown in bold $(P<0.05)$. $* C Z-V>$ controls $(P<0.05)$.

Abbreviations: PANSS, Positive and Negative Syndrome Scale; SA, schizoaffective disorder; SCZ+V, schizophrenia with violent behavior; SCZ-V, schizophrenia without violent behavior; SE, standard error; SES, socioeconomic status (a higher number indicates a lower SES). 
Table 2 Between-group differences in brain activations during viewing of negative emotion pictures

\begin{tabular}{|c|c|c|c|c|c|c|}
\hline \multirow[t]{2}{*}{ Brain regions } & \multirow[t]{2}{*}{ BA } & \multicolumn{3}{|c|}{ Talairach coordinates } & \multirow{2}{*}{$\begin{array}{l}\text { Voxels } \\
\left(\mathrm{mm}^{3}\right)\end{array}$} & \multirow[t]{2}{*}{$\operatorname{Max} T^{*}$} \\
\hline & & $x$ & $y$ & $\mathbf{z}$ & & \\
\hline \multicolumn{7}{|l|}{ Schizophrenia + violence $>$ schizophrenia } \\
\hline $\begin{array}{l}\text { Lingual gyrus, extending to the left middle occipital, } \\
\text { the bilateral cerebellum, the right middle temporal, } \\
\text { and the left fusiform }\end{array}$ & 18 & 0 & -85 & -2 & 98,791 & 5.8 \\
\hline Right middle frontal gyrus & 10 & 33 & 53 & 10 & 1,217 & 3.8 \\
\hline Right inferior frontal gyrus/superior temporal gyrus & $13 / 38$ & 33 & 8 & -11 & 903 & 4.3 \\
\hline Right globus pallidus & - & 24 & -16 & -8 & I,027 & 3.7 \\
\hline Right precuneus & 7 & 21 & -73 & 37 & 728 & 4.0 \\
\hline Anterior cingulate gyrus & 32 & 3 & 38 & -2 & 2,159 & 4.1 \\
\hline Mid-cingulate gyrus & 24 & 3 & -4 & 31 & I,027 & 4.1 \\
\hline Left globus pallidus & - & -21 & -13 & -5 & 2,052 & 4.5 \\
\hline Left precentral gyrus & 6 & -42 & -4 & 31 & $\mathrm{I}, 828$ & 4.1 \\
\hline Schizophrenia $>$ schizophrenia + violence & None & & & & & \\
\hline Controls $>$ schizophrenia + violence & None & & & & & \\
\hline \multicolumn{7}{|l|}{ Schizophrenia + violence $>$ control } \\
\hline $\begin{array}{l}\text { Right fusiform gyrus, extending to the right lingual } \\
\text { gyrus and the right inferior temporal }\end{array}$ & 19 & 36 & -73 & -8 & 12,498 & 5.5 \\
\hline Right superior frontal gyrus & 9 & 15 & 38 & 40 & 362 & 3.8 \\
\hline Anterior cingulate gyrus & 32 & 3 & 44 & 4 & $|, 03|$ & 4.0 \\
\hline Left lingual gyrus & - & -18 & -79 & -17 & 1,852 & 4.2 \\
\hline Left precentral gyrus & 6 & -39 & -1 & 34 & ।,389 & 4.4 \\
\hline \multicolumn{7}{|l|}{ Controls $>$ schizophrenia } \\
\hline Right superior temporal gyrus & 38 & 33 & 17 & -29 & 402 & 4.4 \\
\hline Cerebellum (tonsil) & - & -6 & -37 & -41 & 1,619 & 4.4 \\
\hline Posterior cingulate gyrus & 29 & -3 & -37 & 13 & 6,264 & 4.5 \\
\hline Left cerebellum (tonsil) & - & -30 & -49 & -38 & 614 & 3.7 \\
\hline Left hippocampus & - & -33 & -31 & -8 & 1,905 & 3.9 \\
\hline Left inferior parietal & 40 & -42 & -52 & 46 & 2,579 & 4.2 \\
\hline Left superior temporal gyrus & 39 & -48 & -52 & 22 & 765 & 3.9 \\
\hline Schizophrenia $>$ controls & None & & & & & \\
\hline
\end{tabular}

Notes: $* T$-value of the highest peak within the cluster to significantly differ between groups; $P<0.00$ I.

Abbreviation: BA, Brodmann area.

right precuneus, the anterior and mid-cingulate gyrus, and the left precentral gyrus. Relative to controls, $\mathrm{SCZ}+\mathrm{V}$ showed increased activations in the right fusiform gyrus, the right superior frontal gyrus, the anterior cingulate gyrus, the left lingual gyrus, and the left precentral gyrus. Finally, relative to controls, SCZ-V had decreased activations in temporal, parietal, paralimbic, and cerebellar regions (Table 2).

\section{Conjunction analyses}

Since SCZ+V had increased activations compared to SCZ-V and controls, spatial conjunction analyses were performed to identify neural differences common to both group comparisons. As illustrated in Table 3, spatial conjunction analyses revealed four intersections between the " $\mathrm{SCZ}+\mathrm{V}$ minus SCZ-V" and the "SCZ+V minus Controls" contrasts, namely the right lingual gyrus, the left lingual gyrus, the anterior cingulate gyrus, and the left precentral gyrus (Figure 1). Hyperactivations in these clusters remained significant after controlling for positive and disorganized symptoms, clozapine, and parental SES. Among participants with SCZ, no significant correlations were observed between regional brain activity and subjective ratings of negative images and antisocial personality traits (all $P$-values $>0.05$ ).

Table 3 Spatial conjunction analyses for the Negative minus Neutral contrast

\begin{tabular}{|c|c|c|c|c|c|c|}
\hline \multirow[t]{2}{*}{ Brain regions } & \multirow[t]{2}{*}{ BA } & \multicolumn{3}{|c|}{$\begin{array}{l}\text { Talairach } \\
\text { coordinates }\end{array}$} & \multirow[t]{2}{*}{$\begin{array}{l}\text { Voxels } \\
\left(\mathrm{mm}^{3}\right)\end{array}$} & \multirow[t]{2}{*}{$\operatorname{Max} T^{*}$} \\
\hline & & $x$ & $y$ & $\mathbf{z}$ & & \\
\hline \multicolumn{7}{|c|}{ Schizophrenia + violence $>$ schizophrenia and controls } \\
\hline Right lingual gyrus & 18 & 3 & -85 & -2 & 7,471 & 5.6 \\
\hline Left lingual gyrus & 18 & -15 & -82 & -17 & $\mathrm{I}, 807$ & 5.1 \\
\hline Anterior cingulate gyrus & 24 & 3 & 38 & 0 & 320 & 4.0 \\
\hline Left precentral gyrus & 6 & -42 & -4 & 31 & 980 & 4.1 \\
\hline
\end{tabular}

Notes: $* T$-value for the highest peak within the cluster to significantly differ between groups; $P<0.001$.

Abbreviation: BA, Brodmann area. 


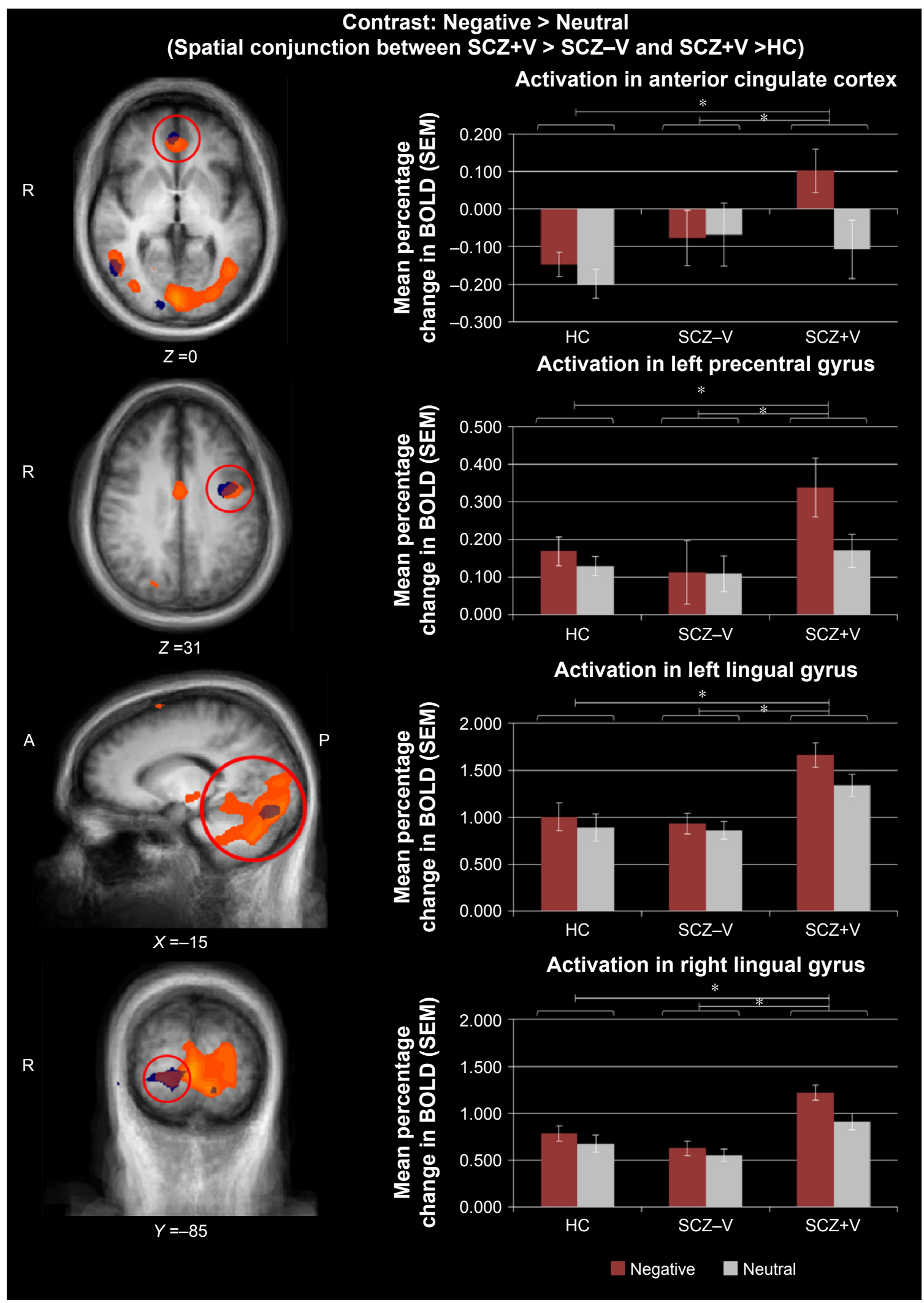

Figure I Spatial conjunction analyses for the Negative minus Neutral contrast.

Notes: The figure displays the four intersections between $(\mathrm{SCZ}+\mathrm{V}>\mathrm{SCZ}-\mathrm{V})$ and $(\mathrm{SCZ}+\mathrm{V}>\mathrm{HC})$ comparisons $\left({ }^{*} T\right.$-value for the highest peak within the cluster to significantly differ between groups; $P<0.00$; ; cluster threshold $343 \mathrm{~mm}^{3}$ ). Results for $\mathrm{SCZ}+\mathrm{V}>\mathrm{HC}$ comparison are displayed in blue, and for the $\mathrm{SCZ}+\mathrm{V}>\mathrm{SCZ}-\mathrm{V}$ comparison in orange. Bar graphs refer to means and SEMs.

Abbreviations: A, anterior; BOLD, blood oxygen level dependent; HC, healthy controls; $\mathrm{P}$, posterior; $\mathrm{R}$, right; SCZ+V, schizophrenia patients with violent behavior; SCZ-V, schizophrenia patients without violent behavior; SEM, standard error of the mean. 


\section{Groups comparisons of neural activity during presentation of positive pictures}

For the Positive minus Neutral contrast, no differences were observed between SCZ+V and SCZ-V, or between SCZ-V and controls. Relative to controls, SCZ-V had decreased activations in the left lingual gyrus/cerebellar culmen $(x=-15$; $y=-31 ; z=-14 ; t=3.8 ; P<0.001 ; 571$ voxels $)$. Among the participants with SCZ, no significant correlations were observed between regional brain activity and subjective ratings of positive images, and antisocial personality traits (all $P$-values $>0.05)$.

\section{Groups comparisons of neural activity during presentation of neutral pictures}

As presented in Table 4, for the Neutral minus Rest contrast, relative to $\mathrm{SCZ}-\mathrm{V}, \mathrm{SCZ}+\mathrm{V}$ showed increased activations in the right inferior temporal gyrus, the bilateral middle occipital gyrus, the medial frontal gyrus, and the left cerebellar tuber. Relative to controls, $\mathrm{SCZ}+\mathrm{V}$ displayed increased activations in the right middle frontal gyrus, the right and medial superior frontal gyrus, the bilateral superior temporal gyrus, the right superior parietal gyrus, the right cuneus, the left caudate nucleus, the left postcentral gyrus, the left lingual gyrus, and the left inferior occipital gyrus. Relative to controls, SCZ-V showed increased activations in the left inferior parietal gyrus (Table 3).

\section{Conjunction analyses}

As illustrated in Table 5, spatial conjunction analyses revealed four intersections between the " $\mathrm{SCZ}+\mathrm{V}$ minus SCZ" and the "SCZ+V minus Controls" contrast, namely the right middle occipital gyrus, the left lingual gyrus, the left middle occipital gyrus, and the left fusiform gyrus (Figure 2). Hyperactivations in these clusters remained significant after controlling for positive and disorganized symptoms, clozapine, and parental SES. Among participants with SCZ, no significant correlations were observed between regional brain activity and subjective ratings of neutral images, and antisocial personality traits (all $P>0.05$ ).

Results of within-group contrasts (Negative $>$ Neutral; Positive $>$ Neutral) are provided in Tables S1 and S2.

\section{Discussion}

This is the first study to identify neural alterations in the processing of negative and neutral emotions among men with schizophrenia and a history of violent behavior as compared

Table 4 Between-group differences in brain activations during viewing of neutral images

\begin{tabular}{|c|c|c|c|c|c|c|}
\hline \multirow[t]{2}{*}{ Brain region } & \multirow[t]{2}{*}{ BA } & \multicolumn{3}{|c|}{ Talairach coordinates } & \multirow{2}{*}{$\begin{array}{l}\text { Voxels } \\
\left(\mathrm{mm}^{3}\right)\end{array}$} & \multirow[t]{2}{*}{$\operatorname{Max} T^{*}$} \\
\hline & & $x$ & $y$ & $\mathbf{z}$ & & \\
\hline \multicolumn{7}{|l|}{ Schizophrenia + violence $>$ schizophrenia } \\
\hline Right inferior temporal gyrus & 37 & 57 & -46 & -23 & 462 & 4.1 \\
\hline $\begin{array}{l}\text { Left middle occipital gyrus, extending to the right middle } \\
\text { occipital, the lingual gyrus, and the bilateral fusiform gyrus }\end{array}$ & 19 & -36 & -82 & 4 & 42,793 & 5.3 \\
\hline Medial frontal gyrus & II & 0 & 44 & -17 & 355 & 4.0 \\
\hline Left cerebellar tuber & - & -57 & -49 & -29 & 496 & 3.9 \\
\hline Schizophrenia $>$ schizophrenia + violence & None & & & & & \\
\hline Controls $>$ schizophrenia + violence & None & & & & & \\
\hline \multicolumn{7}{|l|}{ Schizophrenia + violence $>$ controls } \\
\hline Right middle frontal gyrus & 9 & 60 & II & 37 & $|5,54|$ & 4.9 \\
\hline Right superior temporal gyrus & 38 & 42 & 17 & -23 & 904 & 3.7 \\
\hline Right superior parietal & 7 & 30 & -55 & 46 & 2,987 & 4.3 \\
\hline Right cuneus & 18 & 21 & -91 & 16 & 1,080 & 3.8 \\
\hline Left caudate nucleus & - & -15 & 17 & -2 & 5,679 & 4.6 \\
\hline Superior frontal gyrus & 9 & -3 & 59 & 28 & 1,206 & 3.9 \\
\hline Left postcentral gyrus & 40 & -48 & -31 & 52 & 14,975 & 5.2 \\
\hline Left lingual gyrus & 18 & -12 & -82 & -20 & 1,031 & 3.8 \\
\hline Left inferior occipital & 19 & -48 & -82 & -5 & 8,061 & 5.9 \\
\hline Left fusiform gyrus & 19 & -24 & -67 & -17 & 408 & 4.6 \\
\hline Left superior temporal gyrus & 38 & -39 & 5 & -20 & 1,393 & 3.8 \\
\hline Controls $>$ schizophrenia & None & & & & & \\
\hline \multicolumn{7}{|l|}{ Schizophrenia $>$ controls } \\
\hline Left inferior parietal gyrus & 40 & -36 & -46 & 49 & $\mathrm{I}, 007$ & 4.2 \\
\hline
\end{tabular}

Notes: ${ }^{*} T$-value for the highest peak within the cluster to significantly differ between groups; $P<0.00$ I.

Abbreviation: BA, Brodmann area. 
Table 5 Spatial conjunction analyses for the Neutral minus Rest contrast

\begin{tabular}{|c|c|c|c|c|c|c|}
\hline \multirow[t]{2}{*}{ Brain regions } & \multirow[t]{2}{*}{ BA } & \multicolumn{3}{|c|}{$\begin{array}{l}\text { Talairach } \\
\text { coordinates }\end{array}$} & \multirow[t]{2}{*}{$\begin{array}{l}\text { Voxels } \\
\left(\mathrm{mm}^{3}\right)\end{array}$} & \multirow[t]{2}{*}{$\operatorname{Max} T^{*}$} \\
\hline & & $x$ & $y$ & $\mathbf{z}$ & & \\
\hline \multicolumn{7}{|c|}{ Schizophrenia + violence $>$ schizophrenia and controls } \\
\hline Right middle occipital gyrus & 18 & 24 & -94 & 10 & 944 & 3.9 \\
\hline Left lingual gyrus & 18 & -9 & -88 & -17 & 337 & 4.0 \\
\hline Left middle occipital gyrus & 19 & -37 & -82 & 4 & 4,454 & 5.2 \\
\hline Left fusiform gyrus & 19 & -24 & -64 & -14 & 123 & 4.0 \\
\hline
\end{tabular}

Notes: ${ }^{*} T$-value for highest peak within the cluster to significantly differ between groups; $P<0.00$ I.

Abbreviation: BA, Brodmann area.

to men with schizophrenia and no history of violent behavior and healthy nonviolent men. Negative pictures elicited hyperactivations in $\mathrm{SCZ}+\mathrm{V}$ relative to $\mathrm{SCZ}-\mathrm{V}$ and healthy controls in the ACC, the right and left lingual gyrus, and the left precentral gyrus, regardless of arousal intensity. During viewing of neutral stimuli, hyperactivations in $\mathrm{SCZ}+\mathrm{V}$ were relative to SCZ-V and controls in the left and right middle occipital gyrus, the left lingual gyrus, and the left fusiform gyrus. To our knowledge, this is the first study to report that $\mathrm{SCZ}+\mathrm{V}$ attribute a higher intensity of experienced emotion to neutral stimuli than healthy controls, a result consistent with similar observations previously made in nonpsychotic individuals with antisocial behavior. ${ }^{57}$ Regarding positive stimuli processing, we did not observe activations that distinguished $\mathrm{SCZ}+\mathrm{V}$ from either $\mathrm{SCZ}-\mathrm{V}$ or healthy controls. However, when viewing positive emotion pictures, $\mathrm{SCZ}+\mathrm{V}$ showed decreased activations in the left lingual gyrus compared to healthy controls.

The most important finding of the current study is the increase in the ventral ACC reactivity to negative stimuli specifically observed in SCZ+V. The cingulate cortex is crucial in integrating input from many different sources, ${ }^{58}$ and recent studies suggest that the ACC, subdivided into ventral/ rostral/affective and $\mathrm{mid} /$ dorsal/cognitive regions, is key for the integration of negative affect and cognitive control. ${ }^{58-60}$ Indeed, a meta-analysis of fMRI studies suggested that ventral ACC is associated with the generation of emotion, and the dorsal ACC with emotion regulation. ${ }^{61}$ Furthermore, due to important connections with both the amygdala and the orbitofrontal cortex, the ACC appears to be involved in violent behavior as well. ${ }^{23}$ Considering the role of the ACC in emotion processing,,$^{22,59}$ the results of the current study suggest that ventral ACC dysfunctions are associated with negative stimuli processing in $\mathrm{SCZ}+\mathrm{V}$. A meta-analysis that included $450 \mathrm{SCZ}-\mathrm{V}$ reported reduced activity in ACC in relation to emotion processing and emotional experience. ${ }^{62}$
These latter results might reflect a hyperactivation of the ACC during the viewing of emotionally neutral stimuli, as SCZ-V have been reported to assign abnormal salience to neutral stimuli. ${ }^{42-44}$ Nevertheless, the results of the current study show that ACC hyperactivations distinguished SCZ-V from the two other groups. Based on the extant literature, dysfunctions in the prefrontal lobe, amygdala, or subcortical nuclei might have been expected in SCZ+V..$^{16,37,38}$ Negative stimuli did elicit activations in the amygdala within the $\mathrm{SCZ}+\mathrm{V}$ group, although they were not significantly different from the activations elicited in the other two groups. Given that the amygdala is associated with the automatic detection of threat ${ }^{63}$ and that the ACC is associated with the integration of information, ${ }^{58}$ our results might indicate that there is a dysfunction in more elaborate emotion processing among $\mathrm{SCZ}+\mathrm{V}$. Evidence shows that negative emotions may be a factor in precipitating violent behavior. The current findings provide a potential mechanistic explanation for this documented clinical observation. ${ }^{22}$

We also observed a potential influence of image valence on the activity of regions associated with early visual detection (lingual gyrus, fusiform gyrus, middle occipital gyrus) and movement planning (precentral gyrus) in SCZ+V. Activations in the visual cortex during the viewing of emotional stimuli have been frequently reported. ${ }^{64}$ It has been suggested that early processing might be enhanced as a means of providing advantage in information processing to specific emotional stimuli (aversive, appetitive) ${ }^{65}$ It is noteworthy that negative and neutral stimuli elicited hyperactivations in the left lingual gyrus in $\mathrm{SCZ}+\mathrm{V}$ relative to $\mathrm{SCZ}-\mathrm{V}$ and healthy controls, whereas positive stimuli elicited a hypoactivation of the same region in $\mathrm{SCZ}+\mathrm{V}$ compared to healthy controls. This pattern, specific to $\mathrm{SCZ}+\mathrm{V}$, appears to be an attentional bias in early visual detection as a function of valence, which might indicate that visual emotional stimuli are processed differently in this population. Further studies are needed to investigate whether, in fact, this effect is associated with violence. Finally, the hyperactivation of the left precentral gyrus elicited by negative stimuli might indicate an action/ motor preparation. ${ }^{66}$

This study has certain limitations. Participants in both $\mathrm{SCZ}+\mathrm{V}$ and SCZ-V groups were taking antipsychotic medications, which could confound the results. However, the potential effects of antipsychotics on the neural correlates of emotion processing are highly inconsistent. ${ }^{42,67-70}$ Moreover, no group differences were detected in chlorpromazine-equivalent dose, and chlorpromazine equivalents did not correlate with brain activity. Further, the proportions of participants with 


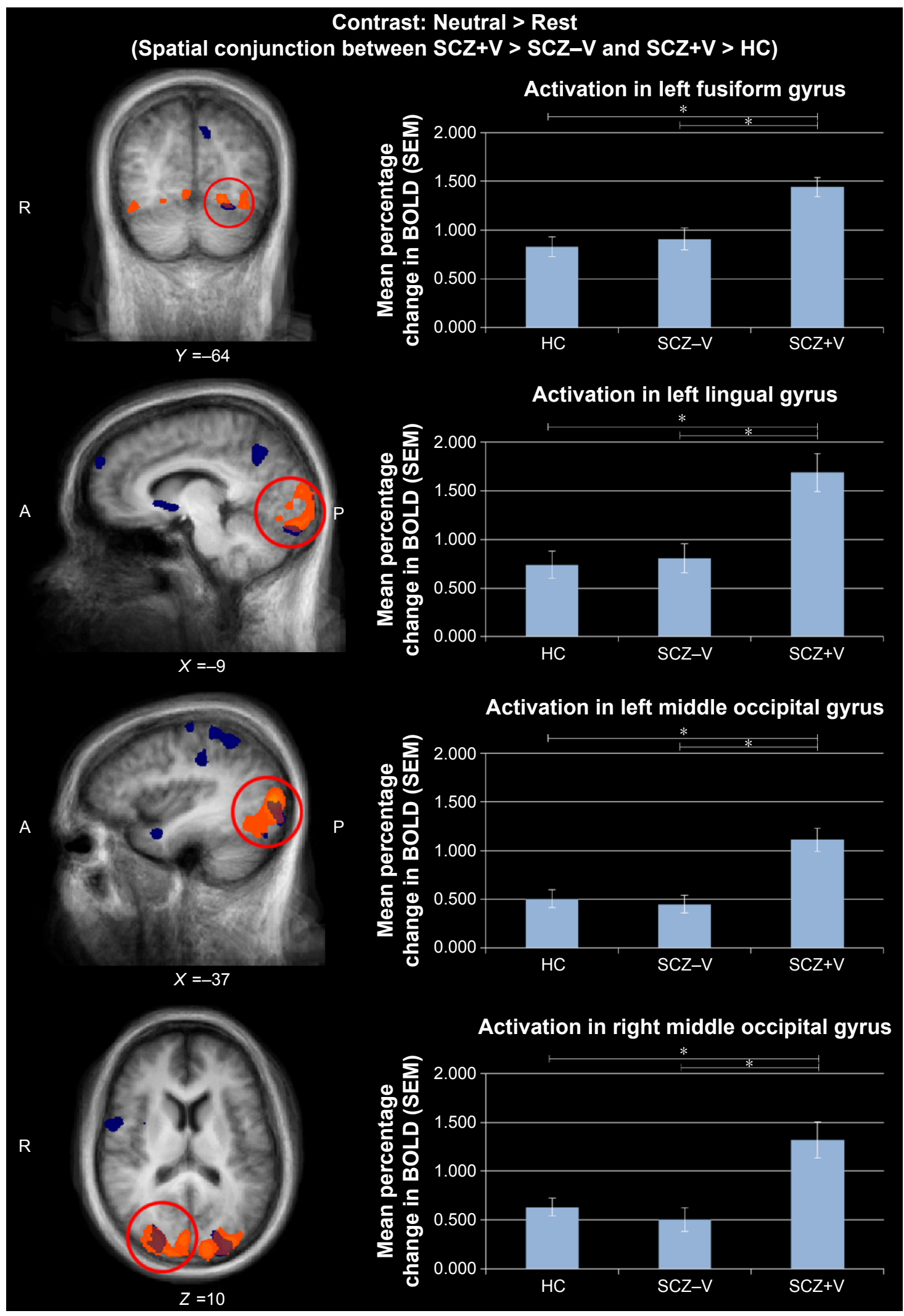

Figure 2 Spatial conjunction analyses for the Neutral minus Rest contrast.

Notes: The figure displays the four intersections between ( $S C Z+V>S C Z-V)$ and $(S C Z+V>H C)$ comparisons (*T-value for the highest peak within the cluster to significantly differ between groups; $P<0.00$ I; cluster threshold $343 \mathrm{~mm}^{3}$ ). Results for $\mathrm{SCZ}+\mathrm{V}>\mathrm{HC}$ comparison are displayed in blue, and for $\mathrm{SCZ}+\mathrm{V}>\mathrm{SCZ}-\mathrm{V}$ comparison in orange. Bar graphs refer to means and SEMs.

Abbreviations: A, anterior; BOLD, blood oxygen level dependent; HC, healthy controls; P, posterior; R, right; SCZ+V, schizophrenia patients with violent behavior; SCZ-V, schizophrenia patients without violent behavior; SEM, standard error of the mean. 
SCZ receiving clozapine did not differ between groups, and clozapine had no significant influence on results. This lack of effect of clozapine may be explained by the fact that the brain regions found to be altered here (eg, anterior cingulate and occipital) are not the ones the most consistently affected by clozapine (eg, striatum). ${ }^{71} \mathrm{SCZ}+\mathrm{V}$ presented fewer positive symptoms than SCZ-V. However, our results remained significant when we entered this potential confound in the analyses. Previous studies have shown that elevated levels of positive symptoms are associated with violence. ${ }^{72,73}$ In fact, positive psychotic symptoms constitute the principal factor associated with violence during an acute psychotic episode, as does a long duration of untreated psychosis. ${ }^{74}$ Once patients are stabilized on antipsychotic medications and present low levels of positive symptoms ( $<3$ on the Positive and Negative Syndrome Scale), neither violent behavior nor other forms of psychosocial functioning are associated with positive symptoms. ${ }^{75} \mathrm{SCZ}+\mathrm{V}$ were characterized by lower parental SES relative to healthy controls, which is consistent with a recent meta-analysis suggesting that low SES might be a risk factor for violence in psychosis. ${ }^{76} \mathrm{We}$ performed analyses of covariances and found that parental SES did not influence the main results. In this study, we did not recruit a group of nonpsychotic violent individuals. Even though we did not observe an effect of antisocial personality on our results, the inclusion of a group of nonpsychotic individuals with violent or antisocial behavior would have eased the interpretation of our findings. In nonpsychotic individuals with violent or antisocial behavior, reductions in ACC volumes were reported in some studies, while others have not confirmed these findings. ${ }^{77} \mathrm{~A}$ few functional neuroimaging studies have observed abnormal ACC activations in violent/ antisocial and nonpsychotic individuals during emotion processing; however, activations were reduced rather than increased. ${ }^{77-79}$ Taken together, the available evidence makes it difficult to determine if our results are explained by an effect of violence or by an interaction between psychosis and violence.$^{80}$ Finally, although IAPS images are well validated for the study of emotional valence and arousal, ${ }^{52}$ the images present in our study and our experimental design were not optimized to investigate discrete emotions such as anger. The study was characterized by several strengths including relatively large samples of men with schizophrenia who underwent detailed assessments of all disorders including substance use disorders, symptoms, and violent behavior. Finally, objective measures showed that no participant had been using substances prior to the brain scan.

\section{Conclusion}

To conclude, this is the first fMRI study to investigate the processing of positive, negative, and neutral stimuli among men with schizophrenia and a history of violence. A potential bias toward image valence in early visual detection was observed among SCZ+V. More importantly, these men displayed ventral ACC dysfunctions when processing negative stimuli. Given the role of the ACC in information integration, these results potentially indicate a dysfunction in more elaborate processes related to emotions among SCZ+V. Future studies are needed to investigate the influence of discrete emotions (anger) and emotion regulation on the ACC of this population.

\section{Acknowledgments}

SP is a holder of the Eli Lilly Chair on Schizophrenia Research and is supported by the Fondation de l'Institut Universitaire en Santé Mentale de Montréal; AT is a holder of a scholarship from Université de Montréal; AD is a holder of Junior 1 salary award from the Fonds de Recherche du Québec en Santé.

\section{Disclosure}

The authors report no conflicts of interest in this work.

\section{References}

1. World Health Organization. Schizophrenia. Geneva, Switzerland: World Health Organization; 2015. Available from: www.who.int/mental_health/ management/schizophrenia/en/. Accessed September 8, 2015.

2. Fazel S, Gulati G, Linsell L, Geddes JR, Grann M. Schizophrenia and violence: systematic review and meta-analysis. PLoS Med. 2009;6(8): e1000120.

3. Grann M, Danesh J, Fazel S. The association between psychiatric diagnosis and violent re-offending in adult offenders in the community. BMC Psychiatry. 2008;8:92.

4. Swanson JW, Holzer CE 3rd, Ganju VK, Jono RT. Violence and psychiatric disorder in the community: evidence from the Epidemiologic Catchment Area surveys. Hosp Community Psychiatry. 1990;41(7):761-770.

5. Volavka J, Citrome L. Pathways to aggression in schizophrenia affect results of treatment. Schizophr Bull. 2011;37(5):921-929.

6. Fazel S, Wolf A, Palm C, Lichtenstein P. Violent crime, suicide, and premature mortality in patients with schizophrenia and related disorders: a 38-year total population study in Sweden. Lancet Psychiatry. 2014;1(1): 44-54.

7. Walsh E, Gilvarry C, Samele C, et al. Predicting violence in schizophrenia: a prospective study. Schizophr Res. 2004;67(2-3):247-252.

8. Silverstein SM, Del Pozzo J, Roché M, Boyle D, Miskimen T. Schizophrenia and violence: realities and recommendations. Crime Psychol Rev. 2015;1(1):21-42.

9. Brennan PA, Mednick SA, Hodgins S. Major mental disorders and criminal violence in a danish birth cohort. Arch Gen Psychiatry. 2000;57(5): 494-500.

10. Short T, Thomas S, Mullen P, Ogloff JR. Comparing violence in schizophrenia patients with and without comorbid substance-use disorders to community controls. Acta Psychiatr Scand. 2013;128(4):306-313.

11. Hodgins $\mathrm{S}$. Violent behaviour among people with schizophrenia: a framework for investigations of causes, and effective treatment, and prevention. Philos Trans R Soc Lond B Biol Sci. 2008;363(1503):2505-2518. 
12. Dumont M, Dumais A, Briand C, Côté G, Lesage A, Dubreucq J-L. Clinical characteristics of patients deemed to require long-term hospitalization in a civil or forensic psychiatric setting. Int J Forensic Ment Health. 2012;11(2):110-118.

13. Tulloch AD, Fearon P, David AS. The determinants and outcomes of long-stay psychiatric admissions: a case-control study. Soc Psychiatry Psychiatr Epidemiol. 2008;43(7):569-574.

14. Hodgins S, Alderton J, Cree A, Aboud A, Mak T. Aggressive behaviour, victimization and crime among severely mentally ill patients requiring hospitalisation. Br J Psychiatry. 2007;191:343-350.

15. Roberton T, Daffern M, Bucks RS. Emotion regulation and aggression. Aggress Violent Behav. 2012;17(1):72-82.

16. Kumari V, Das M, Taylor PJ, et al. Neural and behavioural responses to threat in men with a history of serious violence and schizophrenia or antisocial personality disorder. Schizophr Res. 2009;110(1-3):47-58.

17. Roberton T, Daffern M, Bucks RS. Maladaptive emotion regulation and aggression in adult offenders. Psychol Crime Law. 2014;20(10): 933-954.

18. Tager D, Good GE, Brammer S. "Walking over "em"': an exploration of relations between emotion dysregulation, masculine norms, and intimate partner abuse in a clinical sample of men. Psychol Men Masculin. 2010; 11(3):233-239.

19. Chan SC, Raine A, Lee TM. Attentional bias towards negative affect stimuli and reactive aggression in male batterers. Psychiatry Res. 2010 176(2-3):246-249.

20. Chereji SV, Pintea S, David D. The relationship of anger and cognitive distortions with violence in violent offenders' population: a metaanalytic review. Eur J Psychol Appl Leg Context. 2012;4(1):59-77.

21. Reagu S, Jones R, Kumari V, Taylor PJ. Angry affect and violence in the context of a psychotic illness: a systematic review and meta-analysis of the literature. Schizophr Res. 2013;146(1-3):46-52.

22. Davidson RJ, Putnam KM, Larson CL. Dysfunction in the neural circuitry of emotion regulation - a possible prelude to violence. Science. 2000;289(5479):591-594.

23. Rosell DR, Siever LJ. The neurobiology of aggression and violence. CNS Spectr. 2015;20(3):254-279.

24. Naudts K, Hodgins S. Neurobiological correlates of violent behavior among persons with schizophrenia. Schizophr Bull. 2006;32(3) $562-572$.

25. Joyal CC, Putkonen A, Mancini-Marie A, et al. Violent persons with schizophrenia and comorbid disorders: a functional magnetic resonance imaging study. Schizophr Res. 2007;91(1-3):97-102.

26. Barkataki I, Kumari V, Das M, Taylor P, Sharma T. Volumetric structural brain abnormalities in men with schizophrenia or antisocial personality disorder. Behav Brain Res. 2006;169(2):239-247.

27. Kumari V, Barkataki I, Goswami S, Flora S, Das M, Taylor P. Dysfunctional, but not functional, impulsivity is associated with a history of seriously violent behaviour and reduced orbitofrontal and hippocampal volumes in schizophrenia. Psychiatry Res. 2009;173(1):39-44.

28. Yang Y, Raine A, Han CB, Schug RA, Toga AW, Narr KL. Reduced hippocampal and parahippocampal volumes in murderers with schizophrenia. Psychiatry Res. 2010;182(1):9-13.

29. Wong TH, Lumsden J, Fenton GW, Fenwick PB. Neuroimaging in mentally abnormal offenders. Issues Crim Leg Psychol. 1997;27(49-58).

30. Kumari V, Uddin S, Premkumar P, et al. Lower anterior cingulate volume in seriously violent men with antisocial personality disorder or schizophrenia and a history of childhood abuse. Aust N ZJ Psychiatry. 2014;48(2):153-161.

31. Puri BK, Counsell SJ, Saeed N, Bustos MG, Treasaden IH, Bydder GM. Regional grey matter volumetric changes in forensic schizophrenia patients: an MRI study comparing the brain structure of patients who have seriously and violently offended with that of patients who have not. BMC Psychiatry. 2008;8(Suppl 1):S6.

32. Schiffer B, Leygraf N, Muller BW, et al. Structural brain alterations associated with schizophrenia preceded by conduct disorder: a common and distinct subtype of schizophrenia? Schizophr Bull. 2013; 39(5):1115-1128.
33. Hoptman MJ, Volavka J, Weiss EM, et al. Quantitative MRI measures of orbitofrontal cortex in patients with chronic schizophrenia or schizoaffective disorder. Psychiatry Res. 2005;140(2):133-145.

34. Hoptman MJ, Volavka J, Czobor P, et al. Aggression and quantitative MRI measures of caudate in patients with chronic schizophrenia or schizoaffective disorder. J Neuropsychiatry Clin Neurosci. 2006;18(4): 509-515.

35. Soyka M. Neurobiology of aggression and violence in schizophrenia. Schizophr Bull. 2011;37(5):913-920.

36. Hoptman MJ, Antonius D. Neuroimaging correlates of aggression in schizophrenia: an update. Curr Opin Psychiatry. 2011;24(2):100-106.

37. Dolan MC, Fullam RS. Psychopathy and functional magnetic resonance imaging blood oxygenation level-dependent responses to emotional faces in violent patients with schizophrenia. Biol Psychiatry. 2009;66(6): $570-577$.

38. Hoptman MJ, D'Angelo D, Catalano D, et al. Amygdalofrontal functional disconnectivity and aggression in schizophrenia. Schizophr Bull. 2010;36(5):1020-1028.

39. Gold JM, Waltz JA, Prentice KJ, Morris SE, Heerey EA. Reward processing in schizophrenia: a deficit in the representation of value. Schizophr Bull. 2008;34(5):835-847.

40. Cherek DR, Moeller FG, Dougherty DM, Rhoades H. Studies of violent and nonviolent male parolees: II. Laboratory and psychometric measurements of impulsivity. Biol Psychiatry. 1997;41(5): 523-529.

41. Cohen AS, Minor KS. Emotional experience in patients with schizophrenia revisited: meta-analysis of laboratory studies. Schizophr Bull. 2010;36(1):143-150.

42. Potvin S, Tikasz A, Lungu O, Dumais A, Stip E, Mendrek A. Emotion processing in treatment-resistant schizophrenia patients treated with clozapine: an fMRI study. Schizophr Res. 2015;168(1-2):377-380.

43. Hall J, Whalley HC, McKirdy JW, et al. Overactivation of fear systems to neutral faces in schizophrenia. Biol Psychiatry. 2008;64(1):70-73.

44. Lakis N, Mendrek A. Individuals diagnosed with schizophrenia assign emotional importance to neutral stimuli: an FMRI study. ISRN Psychiatry. 2013;2013:965428.

45. Monahan J, Steadman HJ, Silver E, et al. Rethinking Risk Assessment The MacArthur Study of Mental Disorder and Violence. New York, NY: Oxford University Press; 2001

46. Spitzer RL, Williams JB, Gibbon M, First MB. The structured clinical interview for DSM-III-R (SCID). I: history, rationale, and description. Arch Gen Psychiatry. 1992;49(8):624-629.

47. Woods SW. Chlorpromazine equivalent doses for the newer atypical antipsychotics. J Clin Psychiatry. 2003;64(6):663-667.

48. Kay SR, Fiszbein A, Opler LA. The positive and negative syndrome scale (PANSS) for schizophrenia. Schizophr Bull. 1987;13(2):261-276.

49. Lindenmayer JP, Grochowski S, Hyman RB. Five factor model of schizophrenia: replication across samples. Schizophr Res. 1995;14(3): 229-234.

50. Human Resources and Skills Development Canada. The National Occupational Classification Canada. Ottawa, ON: Human Resources and Skills Development Canada; 2001.

51. Harris GT, Hilton NZ, Rice ME. Explaining the frequency of intimate partner violence by male perpetrators do attitude, relationship, and neighborhood variables add to antisociality? Crim Justice Behav. 2011; 38(4):309-331.

52. Lang PJ, Bradley MM, Cuthbert BN. International Affective Picture System (IAPS): Affective Ratings of Pictures and Instruction Manual. Technical Report A-8. Gainesville, FL: University of Florida; 2008.

53. Talairach J, Tournoux P. Co-planar Stereotaxic Atlas of the Human Brain. Stuttgart, Germany: Thieme Medical; 1988.

54. Boynton GM, Engel SA, Glover GH, Heeger DJ. Linear systems analysis of functional magnetic resonance imaging in human V1.J Neurosci. 1996;16(13):4207-4221.

55. Penny WD, Holmes AJ. Random-effects analysis. In: Frackowiak RSJ, Friston KJ, Frith C, et al, editors. Human Brain Function. 2nd ed. London, UK: Academic Press; 2003. 
56. Ward B. Deconvolution analysis of fMRI time series data. AFNI 3dDeconvolve Documentation. Milwaukee, WI: Medical College of Wisconsin; 2000.

57. Dadds MR, Perry Y, Hawes DJ, et al. Attention to the eyes and fearrecognition deficits in child psychopathy. Br J Psychiatry. 2006;189: 280-281.

58. Bush G, Luu P, Posner MI. Cognitive and emotional influences in anterior cingulate cortex. Trends Cogn Sci. 2000;4(6):215-222.

59. Shackman AJ, Salomons TV, SlagterHA, Fox AS, Winter JJ, Davidson RJ. The integration of negative affect, pain and cognitive control in the cingulate cortex. Nat Rev Neurosci. 2011;12(3):154-167.

60. Amodio DM, Frith CD. Meeting of minds: the medial frontal cortex and social cognition. Nat Rev Neurosci. 2006;7(4):268-277.

61. Kober H, Barrett LF, Joseph J, Bliss-Moreau E, Lindquist K, Wager TD. Functional grouping and cortical-subcortical interactions in emotion: a meta-analysis of neuroimaging studies. Neuroimage. 2008;42(2): 998-1031.

62. Taylor SF, Kang J, Brege IS, Tso IF, Hosanagar A, Johnson TD. Metaanalysis of functional neuroimaging studies of emotion perception and experience in schizophrenia. Biol Psychiatry. 2012;71(2):136-145.

63. Ohman A. The role of the amygdala in human fear: automatic detection of threat. Psychoneuroendocrinology. 2005;30(10):953-958.

64. Phan KL, Wager T, Taylor SF, Liberzon I. Functional neuroanatomy of emotion: a meta-analysis of emotion activation studies in PET and fMRI. Neuroimage. 2002;16(2):331-348.

65. Murphy FC, Nimmo-Smith I, Lawrence AD. Functional neuroanatomy of emotions: a meta-analysis. Cogn Affect Behav Neurosci. 2003;3(3): 207-233.

66. Simon SR, Meunier M, Piettre L, Berardi AM, Segebarth CM, Boussaoud D. Spatial attention and memory versus motor preparation: premotor cortex involvement as revealed by fMRI. J Neurophysiol. 2002;88(4):2047-2057.

67. Roder CH, Dieleman S, van der Veen FM, Linden D. Systematic review of the influence of antipsychotics on the blood oxygenation level-dependent signal of functional magnetic resonance imaging. Curr Med Chem. 2013;20(3):448-461.

68. Roder CH, Hoogendam JM, van der Veen FM. FMRI, antipsychotics and schizophrenia. Influence of different antipsychotics on BOLDsignal. Curr Pharm Des. 2010;16(18):2012-2025.
69. Surguladze SA, Chu EM, Marshall N, et al. Emotion processing in schizophrenia: fMRI study of patients treated with risperidone longacting injections or conventional depot medication. J Psychopharmacol. 2011;25(6):722-733.

70. Stip E, Fahim C, Mancini-Marie A, et al. Restoration of frontal activation during a treatment with quetiapine: an fMRI study of blunted affect in schizophrenia. Prog Neuropsychopharmacol Biol Psychiatry. 2005;29(1):21-26.

71. Mouchlianitis E, McCutcheon R, Howes OD. Brain-imaging studies of treatment-resistant schizophrenia: a systematic review. Lancet Psychiatry. Epub March 3, 2016.

72. Krakowski M, Czobor P. Gender differences in violent behaviors: relationship to clinical symptoms and psychosocial factors. Am J Psychiatry. 2004;161(3):459-465.

73. Steinert T. Prediction of inpatient violence. Acta Psychiatr Scand Suppl. 2002;(412):133-141.

74. Hodgins S, Riaz M. Violence and phases of illness: differential risk and predictors. Eur Psychiatry. 2011;26(8):518-524.

75. Hodgins S, Lincoln T, Mak T. Experiences of victimisation and depression are associated with community functioning among men with schizophrenia. Soc Psychiatry Psychiatr Epidemiol. 2009;44(6):448-457.

76. Witt K, van Dorn R, Fazel S. Risk factors for violence in psychosis: systematic review and meta-regression analysis of 110 studies. PLoS One. 2013;8(2):e55942.

77. Yang Y, Raine A. Prefrontal structural and functional brain imaging findings in antisocial, violent, and psychopathic individuals: a metaanalysis. Psychiatry Res. 2009;174(2):81-88.

78. Kiehl KA, Smith AM, Hare RD, et al. Limbic abnormalities in affective processing by criminal psychopaths as revealed by functional magnetic resonance imaging. Biol Psychiatry. 2001;50(9):677-684.

79. Phillips M. Neural responses to emotional and neutral facial expressions in chronically violent men. J Psychiatry Neurosci. 2010;35(6):390.

80. Hodgins S, Piatosa MJ, Schiffer B. Violence among people with schizophrenia: phenotypes and neurobiology. Curr Top Behav Neurosci. 2014; 17:329-368. 


\section{Supplementary materials}

Table SI Brain activations in each group during negative emotions

\begin{tabular}{|c|c|c|c|c|c|c|}
\hline \multirow[t]{2}{*}{ Brain region } & \multirow[t]{2}{*}{ BA } & \multicolumn{3}{|c|}{ Talairach coordinates } & \multirow{2}{*}{$\begin{array}{l}\text { Voxels } \\
\left(\mathrm{mm}^{3}\right)\end{array}$} & \multirow[t]{2}{*}{$\operatorname{Max} T^{*}$} \\
\hline & & $x$ & y & $\mathbf{z}$ & & \\
\hline \multicolumn{7}{|l|}{ Schizophrenia + violence } \\
\hline \multicolumn{7}{|l|}{ Negative minus Neutral ${ }^{\mathrm{a}}$} \\
\hline $\begin{array}{l}\text { Left fusiform gyrus, extending to the lingual gyrus, } \\
\text { bilateral cerebellum, posterior cingulate, left middle } \\
\text { temporal, thalamus, bilateral amygdala/globus pallidus, } \\
\text { bilateral inferior frontal gyrus }\end{array}$ & 19 & -42 & -67 & -14 & 269,855 & 14.4 \\
\hline $\begin{array}{l}\text { Medial frontal gyrus, extending to the middle frontal } \\
\text { gyrus, anterior cingulate gyrus, and left precentral gyrus }\end{array}$ & 6 & -3 & -20 & 64 & 29,037 & 7.7 \\
\hline Right superior temporal gyrus & 22 & 48 & -7 & -8 & 668 & 4.5 \\
\hline Right subgyral temporal & 20 & 39 & -13 & -20 & 466 & 4.8 \\
\hline Mid-cingulate & 24 & -3 & -4 & 31 & 445 & 4.6 \\
\hline Left cerebellum tonsil & & -18 & -28 & -38 & 363 & 4.7 \\
\hline \multicolumn{7}{|l|}{ Schizophrenia } \\
\hline \multicolumn{7}{|l|}{ Negative minus Neutral } \\
\hline Right fusiform gyrus & 19 & 33 & -79 & -17 & 444 & 4.2 \\
\hline Left fusiform gyrus & 37 & -39 & -58 & -20 & 1,004 & 4.9 \\
\hline \multicolumn{7}{|l|}{ Controls } \\
\hline \multicolumn{7}{|l|}{ Negative minus Neutral } \\
\hline $\begin{array}{l}\text { Brain stem, extending to the bilateral amygdala and the } \\
\text { bilateral superior temporal gyri }\end{array}$ & - & -5 & -23 & -7 & 49,013 & 8.1 \\
\hline Right fusiform gyrus & 37 & 39 & -43 & -11 & 11,359 & 7.8 \\
\hline Left cerebellum tonsil & - & -12 & -40 & -38 & 8,456 & 5.8 \\
\hline Medial frontal gyrus & 9 & 9 & 50 & 19 & $\mathrm{I}, 357$ & 4.8 \\
\hline Posterior cingulate gyrus & 31 & 12 & -43 & 22 & 771 & 4.9 \\
\hline Anterior cingulate gyrus & 24 & 6 & 26 & -5 & 1,330 & 6.0 \\
\hline Left fusiform gyrus & 19 & -36 & -67 & -11 & 22,929 & 8.2 \\
\hline Left middle frontal gyrus & 9 & -45 & 14 & 28 & 1,100 & 4.6 \\
\hline
\end{tabular}

Notes: $* T$-value for the highest peak of activation with the cluster; $P<0.00 \mathrm{I}$. ${ }^{\mathrm{T}}$ The contrast Neutral minus Negative revealed no significant clusters of activations within groups.

Abbreviation: BA, Brodmann area. 
Table S2 Brain activations in each group during positive emotions

\begin{tabular}{|c|c|c|c|c|c|c|}
\hline \multirow[t]{2}{*}{ Brain region } & \multirow[t]{2}{*}{ BA } & \multicolumn{3}{|c|}{$\begin{array}{l}\text { Talairach } \\
\text { coordinates }\end{array}$} & \multirow[t]{2}{*}{$\begin{array}{l}\text { Voxels } \\
\left(\mathrm{mm}^{3}\right)\end{array}$} & \multirow[t]{2}{*}{$\operatorname{Max} T^{*}$} \\
\hline & & $x$ & $y$ & $\mathbf{z}$ & & \\
\hline \multicolumn{7}{|l|}{ Schizophrenia + violence } \\
\hline \multicolumn{7}{|l|}{ Positive minus Neutral } \\
\hline Right middle occipital gyrus & 37 & 48 & -67 & -5 & 5,396 & 5.1 \\
\hline Left fusiform gyrus & 37 & -45 & -61 & -20 & 3,015 & 6.3 \\
\hline \multicolumn{7}{|l|}{ Neutral minus Positive } \\
\hline Right fusiform gyrus & 37 & 27 & -37 & -11 & 953 & 4.1 \\
\hline Left parahippocampal gyrus & 36 & -24 & -40 & -11 & 1,609 & 4.6 \\
\hline Left inferior parietal gyrus & 40 & -39 & -31 & 31 & I,078 & 4.0 \\
\hline \multicolumn{7}{|l|}{ Schizophrenia } \\
\hline \multicolumn{7}{|l|}{ Positive minus Neutral } \\
\hline Left fusiform gyrus & 37 & -45 & -64 & -23 & 401 & 4.0 \\
\hline Neutral minus Positive & \multicolumn{6}{|c|}{ None } \\
\hline \multicolumn{7}{|l|}{ Controls } \\
\hline \multicolumn{7}{|l|}{ Positive minus Neutral } \\
\hline Right middle temporal gyrus & 39 & 42 & -52 & 4 & 9,286 & 7.2 \\
\hline Right amygdala & - & 21 & -10 & -11 & 6,491 & 7.1 \\
\hline Superior frontal gyrus & 9 & -9 & 56 & 28 & 6,182 & 6.9 \\
\hline Precuneus & 7 & 0 & -58 & 31 & 5,951 & 7.1 \\
\hline Anterior cingulate gyrus & 32 & 0 & 38 & -5 & 631 & 4.4 \\
\hline Left middle temporal gyrus & 21 & -51 & -7 & -17 & 14,539 & 7.0 \\
\hline Left middle frontal gyrus & 6 & -36 & 8 & 49 & 467 & 5.1 \\
\hline Left fusiform gyrus & 37 & -39 & -46 & -20 & 1062 & 4.5 \\
\hline \multicolumn{7}{|l|}{ Neutral minus Positive } \\
\hline Left precentral gyrus & 6 & -27 & -19 & 52 & $\mathrm{I}, \mathrm{I} 78$ & 5.5 \\
\hline
\end{tabular}

Notes: $* T$-value for the highest peak of activation within the cluster; $P<0.001$.

Abbreviation: BA, Brodmann area.

\section{Publish your work in this journal}

Neuropsychiatric Disease and Treatment is an international, peerreviewed journal of clinical therapeutics and pharmacology focusing on concise rapid reporting of clinical or pre-clinical studies on a range of neuropsychiatric and neurological disorders. This journal is indexed on PubMed Central, the 'PsycINFO' database and CAS, and is the official journal of The International Neuropsychiatric Association (INA). The manuscript management system is completely online and includes a very quick and fair peer-review system, which is all easy to use. Visit http://www.dovepress.com/testimonials.php to read real quotes from published authors. 